\title{
UMA BREVE REFLEXÃO HISTORIOGRÁFICA SOBRE A TRADUÇÃO AUTOMÁTICA
}

\section{A BRIEF HISTORIOGRAPHICAL REFLECTION ON MACHINE TRANSLATION}

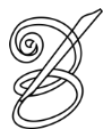 \\ Marcos de Campos Carneiro ${ }^{1}$ \\ Doutorando em Estudos da Tradução (PGET/UFSC) \\ Professor assistente 2 no curso de Línguas Estrangeiras Aplicadas na Universidade de Brasília \\ LEA - UnB - Brasília - Brasil \\ marcosdecc@gmail.com \\ Lincoln P. Fernandes ${ }^{2}$ \\ Doutor em Língua Inglesa e Linguística Aplicada \\ Professor Adjunto no Departamento de Língua e Literatura Estrangeiras \\ PGET - UFSC - Florianópolis - Brasil \\ lico.fernandes@gmail.com
}

Resumo: Este artigo apresenta uma breve reflexão sobre a Tradução Automática (T.A) a partir de uma perspectiva histórica no contexto dos Estudos da Tradução. Em busca de uma maior compreensão sobre alguns dos aspectos mais significativos da área de T.A, consideramos empregar a dicotomia "humano versus automático” para analisar esses dois processos tradutórios distintos. Esta análise consiste em explorar a relação entre o modelo de tradução tripartido de Eugene Nida (tradução humana) e a Abordagem Trifásica dos sistemas de tradução por máquina (tradução automática). Nesse sentido, apresentamos uma síntese da cronologia da Tradução Automática, relacionando-a à evolução da linguística no contexto das gramáticas formais. A partir dos resultados obtidos, propomos uma interpretação das influências e das afinidades observadas entre os processos de tradução humano e automático.

Palavras-chave: Tradução automática; Historiografia da tradução; Eugene Nida.

\begin{abstract}
This paper presents a brief reflection on Machine Translation (MT) from a historical perspective in the context of Translation Studies. In search of a better understanding of some of the most significant aspects of MT, we consider using the "human versus automatic" dichotomy to analyze these two distinct translational processes. This analysis consists of exploring the relationship between the tripartite translation model proposed by Eugene Nida (i.e. human translation) and the three-phase approach for machine translation systems (i.e. machine translation). In this sense, we present a summary of the chronology of machine translation, relating to the evolution of language in the context of formal grammars. From the results obtained, we propose an interpretation of the influences and affinities observed between human and automatic translation processes.
\end{abstract}

Key-words: Machine translation; Historiography of translation; Eugene Nida. 


\section{Introdução}

“Dans le cours de l'histoire, il y a des périodes où les hommes pensent en même temps les mêmes formes. L'influence n'est alors que le moyen des affinités, et l'on peut dire qu'elle ne s'exerce pas en dehors de ces dernières" (FOCILLON, 1943, p. 61).

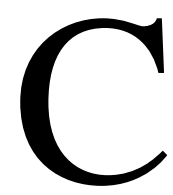
onsiderando a imensidade de enfoques relacionados à arte de escrever a história da tradução, e a complexidade do campo historiográfico, escrevemos a nossa breve versão sobre a história da tradução automática. O seu produto é objeto de debate entre perspectivas distintas de ordem linguísticas e tradutológicas. Devido às muitas significações relacionadas à reescritura dos fatos notáveis que marcaram a evolução da T.A, buscamos interpretações acerca da realidade concebida por seus representantes, baseadas em evidências documentais inscritas no tempo e no espaço.

Por esse motivo, a aplicação do método historiográfico à análise da tradução automática revela-se extremamente complexa. Conforme Mathieu Guidère (2010), “um enfoque histórico só 160 faz sentido se ele retraçar a evolução das ideias tradutológicas e o seu tratamento ao longo do tempo” (p. 22). Desse modo, nossa interpretação sobre a tradução automática, nos conduz a considerar a oposição entre o humano, representado pelo modelo trifásico de tradução de Eugene Nida, e o automático, simbolizado pelas escolhas aplicativas dos sistemas de tradução automática.

Desfazemos assim a ideia de uma descrição puramente cronológica dos eventos marcantes, para que possamos nos ater à investigação de dois fenômenos tradutórios observados em torno dessa dicotomia. Nesse sentido, estabelecer uma analogia entre o modelo tripartido de Nida (humano), e a abordagem trifásica dos sistemas de tradução (automático) encontra um ponto de apoio situado em contextos históricos distintos e complementares. Situamos-nos assim em uma concepção historiográfica da tradução que, segundo Henri Focillon viabiliza o estudo da vida das "formas inteligíveis" (1943) sistemas e modelos, tendo estes a peculiaridade de se repetirem em diferentes períodos e áreas de conhecimento.

Poder reproduzir a coexistência dessas formas inteligíveis presentes em determinados fragmentos do tempo, nos leva a expor uma cronologia da tradução automática associada à evolução das gramáticas formais, buscando interpretar o modelo de Nida de influência chomskyana, para então compará-lo aos sistemas de T.A. Em concordância com Eleonora Brito 
(2002), pensamos que “o passado não estabelece o tipo de leitura que lhe convém”, sendo esse processo de "responsabilidade do historiador" (p. 3). Tendo assim estabelecido nosso método histórico-interpretativo da tradução automática, nos permitimos refletir sobre esse campo de conhecimento, acreditando que historicizar essas formas inteligíveis de concepções linguísticas e tradutológicas seja um caminho para nos aproximarmos cada vez mais de certas "verdades" históricas.

\section{Cronologia da Tradução Automática (T.A)}

A Tradução Automática é uma disciplina relativamente recente. Considerada como uma abordagem vinculada à Linguística se destaca por ter recebido diversas contribuições no decorrer de sua evolução. Segundo Steiner (2005), as pesquisas relacionadas à T.A iniciam-se nos anos 1940, quando "estudiosos e críticos russos e tchecos herdeiros do movimento formalista, aplicam a teoria linguística e a estatística à tradução” (p. 260).

De fato, a T.A inicia-se em 1946 como uma ferramenta destinada a fins estratégicos, vinculada ao surgimento da Guerra Fria, para ter seu uso interrompido vinte anos depois, pelo Comitê Avaliador do Processamento Automático de Linguagem, Automatic Language Processing Advisory Commitee (ALPAC). Nesse período, os avaliadores consideraram que os sistemas em voga não funcionavam corretamente, decidindo então tratar apenas da Tradução Assistida por Computador, Computer-Aided Translation (CAT). A partir de então, Booth (1967) publica a "Máquina de traduzir", marcando uma nova fase na constituição da área. Abaixo aparecem representados os principais fatos históricos relacionados à tradução automática: 


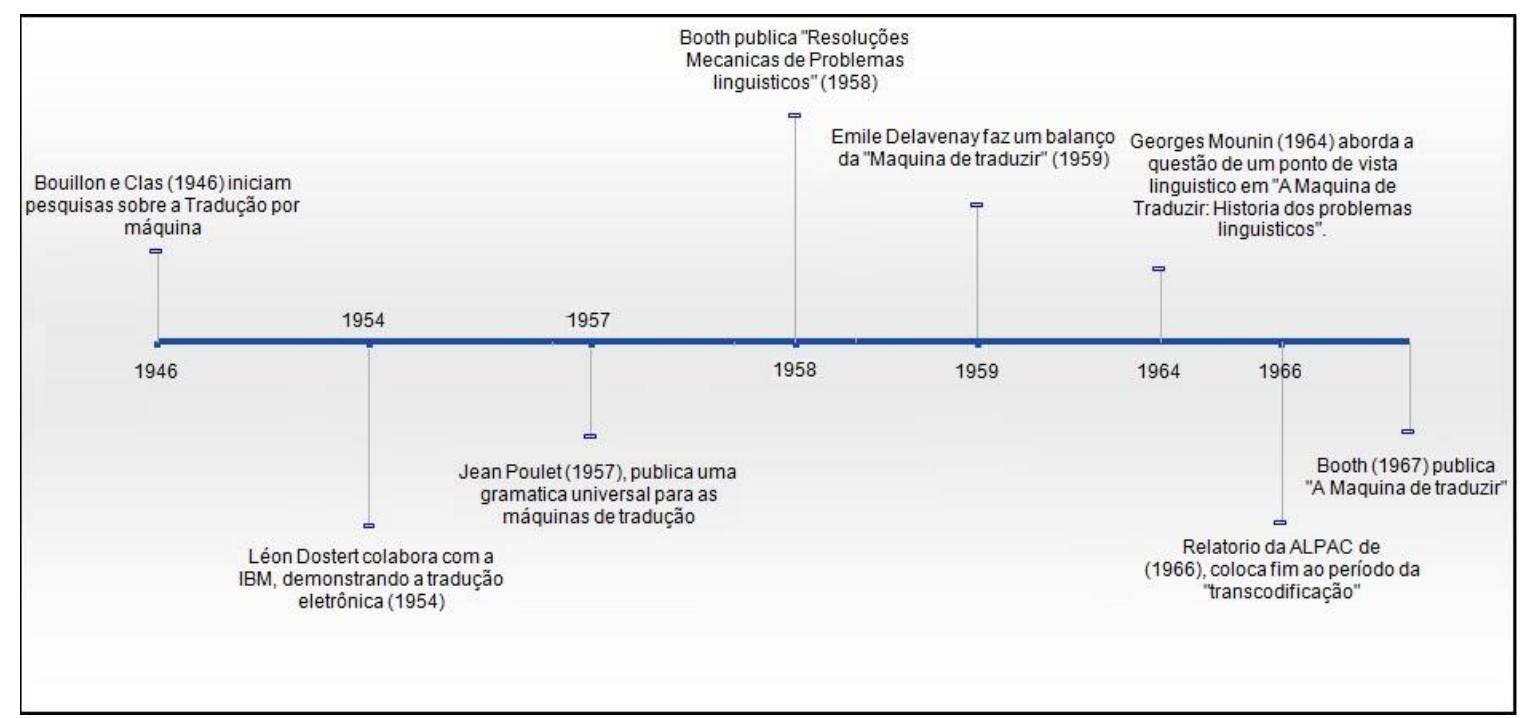

Figura 1: Cronologia resumida dos fatos marcantes na evolução da T.A.

Igualmente conhecida por tradútica ou tradução por máquina, a T.A "refere-se a sistemas informáticos responsáveis por traduções produzidas com ou sem a assistência humana" (HUTCHINS, 2003, p. 501). Caracterizamos assim a sua evolução como um acontecimento vinculado ao surgimento dos primeiros computadores e à criação da área da informática ${ }^{3}$.

No entanto, sob um enfoque puramente linguístico, podemos dizer que a T.A tenha sido influenciada por Ferdinand de Saussure (1916), fazendo com que a estrutura da linguagem se tornasse analisável e estudada. Isso porque, considerando o caráter de cientificidade de sua abordagem, propõe-se um exame de como os elementos da linguagem interagem no momento presente e de forma sincrônica, deixando de lado os estudos diacrônicos. Centrando-se sobre a língua, considerada como um sistema de expressão subjacente à fala, as abordagens anteriores dos estudos da linguagem, baseadas na relação entre as palavras e as coisas designadas no mundo foram postas de lado. Sob sua perspectiva estrutural, Saussure defende que a relação a ser estabelecida deve girar em torno das duas faces do signo linguístico, compostas por um significante e por um significado.

O estruturalismo encontra assim a figura de Bloomfield (1933), desejoso de tornar a linguística uma ciência exata, a partir de suas descrições científicas da linguagem, sendo assim ilegítimo hipotetizar sobre o que se produz no cérebro dos locutores. No desenrolar da corrente das gramáticas formais, cujo precursor foi Lucien Tesnière (1959), chegamos a Noam Chomsky 
(1957) com a sua concepção de gramática gerativa transformacional, ficando então estabelecido o caráter matemático de seu sistema de regras, para dar lugar aos modelos formais visando aplicações informáticas.

Em concordância com Bassnett (2003), acreditamos ser "virtualmente impossível dividir períodos por datas, porque, como afirma Lotman, a cultura humana é um sistema dinâmico. As tentativas para situar estádios de desenvolvimento dentro de limites temporais estritos contradizem esse dinamismo” (p. 260). Sendo assim, também optamos por mencionar que a tradução automática (T.A) é uma das aplicações da linguística computacional. Inseridas nesse contexto encontram-se as atividades de recuperação da informação, e as interfaces homemmáquina, centradas no desenvolvimento de sistemas capazes de tratar e processar as línguas ditas naturais.

Nesse sentido consideramos a necessidade de situar a T.A, assim como a Linguística Computacional, no mesmo continuum das gramáticas formais, para chegarmos à exposição do processo tradutório automático e humano que temos em vista. Dentro da concepção gramatical de Chomsky, o sentido é gerado por uma transformação da estrutura profunda à estrutura de superfície. Como veremos na seguinte seção, seu sistema de gramática gerativa transformacional veio influenciar Eugene Nida a idealizar o processo tripartido de tradução que nos propomos a resgatar, e sobre o qual estabelecemos uma analogia com as escolhas teóricas dos sistemas de Tradução Automática.

As escolhas teóricas relacionadas à tradução automática envolvem abordagens linguísticas das mais diversas. Dentre elas destacam-se a abordagem lexical, sintática, ontológica, sistêmica e probabilística (para uma visão mais abrangente sobre o assunto, vide SANTOS, 2014 e SILVA, 2010). A partir da abordagem lexical foi desenvolvida a primeira geração de sistemas de T.A, em que itens lexicais de uma língua fonte são levados a estabelecer suas correspondências em um arquivo de dados no qual são substituídos, para então serem reestruturados em itens lexicais de uma língua fonte. Ressalta-se que o processo de tradução tripartido da abordagem descrita se faz presente nas demais. Conforme mencionado por Federica Scarpa (2009):

pode-se dizer que o processo tradutório dos sistemas de tradução automática tradicionais compõe-se de três etapas principais: a análise das frases do texto de partida, graças a algoritmos (análise sintática ou parseamento), transferência de uma língua para outra graças a um dicionário bilíngue e as regras de transformação lexical, e a produção ou síntese do texto de chegada. (p. 350) 
Com base, então, nessas três etapas da tradução automática descrita por Scarpa (idem), adentramos o campo disciplinar dos Estudos da Tradução, para que possamos de forma objetiva localizar e comparar o sistema tripartido de Nida (1969) com o processo tradutório dos sistemas de T.A.

\section{A influência da abordagem linguística na tradução}

Como vimos anteriormente, o desenvolvimento dos estudos da tradução é entremeado por diversas correntes linguísticas que devem ser consideradas, na busca pelo entendimento do fenômeno de tradução automática. Considerando o estabelecimento da analogia que engendramos, revisitamos o sistema tripartido de Nida, que pela linguística gerativatransformacional, tinha como pressuposto a criação de uma teoria da tradução a partir de suas concepções do saber linguístico. Embora Nida não seja mencionado na literatura da T.A, meditamos assim o encontro dos estudiosos da tradução com o que se “começa a chamar de tradútica, a mais recente das disciplinas que, na esteira da informática, da prodútica etc., querem agora anexar os “processos de tradução” aos seus sistemas de computação” (BERMAN, 2012, p. 24).

A perspectiva normativa de Nida (1969), fundamentada na linguística chomskyana, permitiu descrever o modo pelo qual o sentido de unidades de tradução é transferido de uma língua para outra. A influência do gerativismo de Chomsky (1957), em que se apóia Nida, baseiase nos conceitos estrutura profunda e de estrutura de superfície. Para Chomsky, o sistema de sua gramática transformacional é composto de uma estrutura de superfície, contendo os sons e as palavras em uma frase, e de uma estrutura profunda na qual estaria o sentido.

A partir disso, Nida propõe um entendimento tripartido do processo de tradução, dividindo-o em fases a serem percorridas por itens constituintes de uma língua-fonte até a línguaalvo, conforme se pode observar no esquema abaixo: 


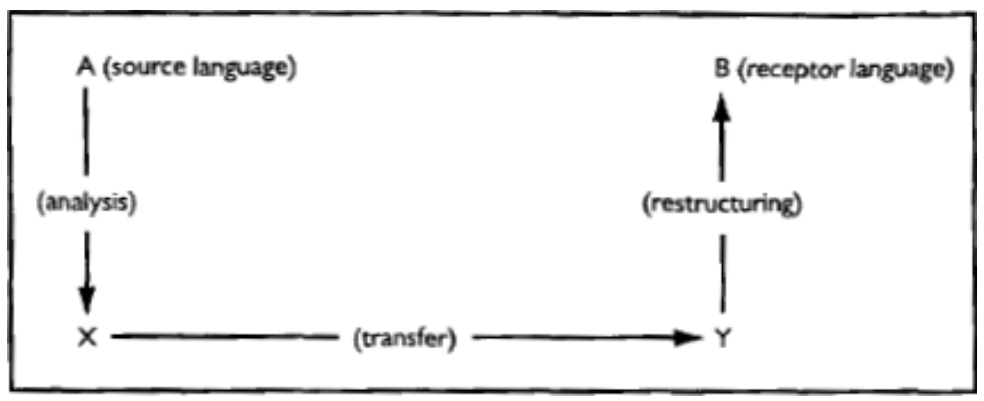

Figura 2: Sistema de tradução (NIDA, 1969, p. 33) ${ }^{4}$

Nesse percurso, os constituintes linguísticos são analisados pelos tradutores da línguafonte (estrutura de superfície), na estrutura profunda em que as relações entre estes constituintes são explicados até serem transferidas e reestruturadas na língua-alvo (estrutura de superfície). É interessante relembrar que a sucessão dessas etapas ocorre de forma comparável à maioria dos softwares de tradução desenvolvidos no século XX, o que se configura como um ponto comum para tratarmos da nossa dicotomia "humana versus automático”.

Conforme mencionamos, este processo tradutório concebido por Nida, tem tido sua autoria omitida pela área de T.A. Já nos estudos gerais da tradução, os estudiosos parecem se distanciar ${ }^{5}$ de seu modelo tripartido, considerando-o de aplicação duvidosa. Nas palavras de Jeremy Munday (2001), “enquanto as técnicas para analisar o sentido e transformar núcleos em estruturas de superfície do texto-alvo são realizadas de forma sistemática, permanece ainda discutível se um tradutor segue estes procedimentos na prática” (p. 34). Tal fato nos leva a supor que essa identidade de relações, entre o humano e o automático, deva-se ao caráter cíclico da vida das formas tripartidas, que reaparecem em diferentes contextos, sem que haja necessariamente uma relação direta de causa e efeito entre essas formas.

Até onde sabemos, muito pouco tem sido realizado no que tange a integração de modelos humanos e automáticos para o melhoramento dos sistemas de tradução automática (vide Bond, 2002 \& Weininger, 2004). No entanto, acreditamos que o diálogo entre esses dois modelos possa gerar resultados bastante positivos no que diz respeito não só ao melhoramento de práticas tradutórias, mas também da compreensão do processo tradutório com um todo. Nesse sentido, sistemas de tradução automática híbridos envolvendo tecnologias de Mineração de Textos, Estatística e Corpora Eletrônicos têm certamente muito a oferecer à pesquisa, ensino e prática da tradução. 


\section{Considerações finais}

Buscamos estabelecer uma analogia entre o modelo tradutório trifásico de Nida e as abordagens dos sistemas de tradução por máquina. Desse modo tentamos associar essas “invenções tradutológicas” ao quadro historiográfico da tradução automática, ancoradas à dicotomia humano versus automático. Isso porque o método historiográfico que propusemos prioriza o julgamento do historiador-tradutor, tendo este uma importância maior do que é geralmente dado à cronologia puramente historiográfica. Entretanto, para representarmos o momento vivenciado por esses processos tradutórios, tivemos de observar os acontecimentos marcantes na área da tradução automática e da linguística, determinando o "movimento do espírito” que se envolve no contexto da vida de onde surgem essas invenções. Inspirados pelo “caráter da constância do espírito humano”, conforme os esclarecimentos de Henri Focillon, expostos na epígrafe deste artigo retomamos o entendimento das formas tripartidas, e a existência de afinidades entres concepções tradutológicas aparentemente distintas e de certa forma complementares.

\section{REFERÊNCIAS BIBLIOGRÁFICAS}

BASSNETT, Susan. Estudos de Tradução. Fundamentos de uma disciplina. Lisboa: Fundação Calouste Gulbenkian, 2003. Tradução de Vivina de Campos Figueiredo; revisão de Ana Maria Chaves.

BERMAN, Antoine. A tradução e a letra ou o albergue do longínquo. Tubarão: Corpiart; Florianópolis, 2013. Tradução de Marie-Hélène C. Torres, Mauri Furlan, Andreia Guerini; revisão de Luana Ferreira de Freitas, Marie-Hélène C. Torres, Mauri Furlan, Orlando Luiz de Araújo.

BOND, F. Toward a Science of Machine Translation. Disponível em http://www.mtarchive.info/TMI-2002-Bond.pdf, 2002.

BOUILLON, Pierrette et CLAS, André. La traductique. Universités francophones. Montréal: Les Presses de l'Université de Montréal, 1993.

BRITO, Eleonora Z. C. D. Em tono da complexidade do campo historiográfico. Revista NetHistória: Para compreender, registrar e formar. Disponível em: <http://www.nethistoria.com.br/secao/ensaios/330/em_torno_da_complexidade_do_campo_histo riografico_/>. Acesso em: 26 jul. 2014.

CHEVALIER Jean-Claude. Histoires des grammaires. In: Encyclopedia Universalis, CD-ROM: 
Version 7, 2003

FOCILLON, Henri. Vie des Formes: suivi de l'éloge de la main. Presses de France. Une édition électronique réalisée à partir du livre de Henri Focillon, Vie des formes, suivi de Eloge de la main. Paris: Presses Universitaires de France, 1943.

FUCHS, Catherine. Théories linguistiques. Encyclopedia Universalis. Disponível em: $<$ http://www.universalis.fr/encyclopedie/linguistique-theories/ressources/>. Acesso em 23 jul. 2014

GENTZLER, Edwin. Teorias contemporâneas da tradução. Tradução de Marcos Malvezzi. São Paulo: Madras, 2009.

GUIDÈRE, Mathieu. Introduction à la traductologie. Penser la traduction : hier, aujourd'hui, demain. De Boeck Supérieur s.a. Paris: Bibliothèque nationale, 2010.

HUTCHINS, John. Machine Translation: general overview. In: Mitkov, Ruslan. The Oxford Handbook of Computational Linguistics. Oxford University Press Inc. New York, 2009.

L'HOMME, Marie-Claude. Initiation à la traductique. Brossard : Linguatech éditeur Inc., 2e édition, 2008.

LOFFLER-LAURIAN, Anne-Marie. La Traduction Automatique, Villeneuve d'Ascq (Nord), Presses Universitaires du Septentrion, 1996.

MUNDAY, Jeremy. Introducing Translation Studies: theories and applications. Routledge London and New York; First published 2001.

NIDA, Eugene. (1964). Principles of correspondence. In: Venuti, Lawrence. The Translation Studies Reader. Advisory Editor: Mona Baker. Routledge London and New York. p. 127-140. Fisrt Published 2000.

SANTOS, Cleydstone C. Por uma Linguagem Controlada na Tradução Automática de Resumos Acadêmicos. Tese de Doutorado, Florianópolis: PPGET/UFSC, 2014.

SAUSSURE, Ferdinand de. Cours de linguistique générale. Payot, 1916. [ouvrage posthume, rédigé d'après les notes de ses étudiants]

SILVA, Fernando. Análise comparativa dos resultados de Mecanismos de Tradução Automática baseados em regras e estatística. Dissertação de Mestrado, Florianópolis: PPGET/UFSC, 2010.

SCARPA, Federica. La traduction spécialisée. Une approche professionnelle à l'enseignement de la traduction. Traduit et adapté par Marco A. Fiola Les Presses de l'Université d'Ottawa, 2010.

STEINER, George. Depois de Babel: questões de linguagem e tradução. Traduzido da $3^{\mathrm{a}}$ edição de 1998, por Carlos Alberto Faraco. Curitiba: Editora da UFPR, 2005. 
WEININGER, Markus. TM e MT na Tradução Técnica Globalizada: tendências e consequências. UFSC, Cadernos de Tradução, v.2, n.4, 2004.

1 Currículo lattes Marcos de Campos Carneiro. Disponível em: http://lattes.cnpq.br/4189312022390606

${ }^{2}$ Currículo lattes Lincoln P. Fernandes. Disponível em: http://lattes.cnpq.br/5335420723422886

${ }^{3}$ Segundo Oustinoff, "O advento da informática, surgida ao final da Segunda Guerra Mundial, poderia levar a crer que, finalmente, seria possível construir "máquinas de traduzir" que livrariam o homem da maldição babélica" (2003, p. 112).

${ }^{4}$ Trata-se de uma ilustração representando o sistema tripartido de Eugene Nida, conforme exposto em Munday (2001, p. 40).

${ }^{5}$ Conforme Edwin Gentzler, "estudiosos da tradução também se distanciam de teorias como as de Chomsky e Nida, que são mais voltadas para os componentes gerativos de estrutura profunda que para as características de estrutura superficial” (2009, p. 112).

RECEBIDO EM: 27 de maio de 2015

ACEITO EM: 20 de junho de 2015 